\title{
Risk of left atrial appendage thrombus in older patients with atrial fibrillation
}

Monika Gawałko ${ }^{1}$, Monika Budnik ${ }^{1}$, Beata Uziębło-Życzkowska², Iwona Gorczyca³ ${ }^{3}$ Paweł Krzesiński², Piotr Scisło ${ }^{1}$, Janusz Kochanowski ${ }^{1}$, Anna Michalska ${ }^{4}$, Olga Jelonek ${ }^{3}$, Katarzyna Starzyk ${ }^{3}$, Agnieszka Jurek², Marek Kiliszek², Beata Wożakowska-Kapłon³.4, Grzegorz Gielerak², Krzysztof J. Filipiak ${ }^{1}$, Grzegorz Opolski ${ }^{1}$, Agnieszka Kapłon-Cieślicka ${ }^{1}$

\author{
${ }^{1} 1^{\text {st }}$ Department of Cardiology, Medical University of Warsaw, Warsaw, Poland \\ 2Department of Cardiology and Internal Diseases, Military Institute of Medicine, \\ Warsaw, Poland \\ ${ }^{3} 1^{\text {st }}$ Clinic of Cardiology and Electrotherapy, Swietokrzyskie Cardiology Centre, Kielce, \\ Poland \\ ${ }^{4}$ Faculty of Medical and Health Sciences, The Jan Kochanowski University, Kielce, \\ Poland
}

Submitted: 3 June 2020

Accepted: 4 August 2020

Arch Med Sci 2020; 5:

DOI: https://doi.org/10.5114/aoms/126028

Copyright ( $)$ Termedia \& Banach

\section{Abstract}

Introduction: We aimed to compare the prevalence of left atrial appendage (LAA) thrombus and its predictors between old and young patients with atrial fibrillation (AF).

Material and methods: The study included 1970 patients aged $\geq 65$ ( $n=$ 822 [41.7\%]) and $<65(n=1148$ [58.3\%]) referred for AF cardioversion or ablation preceded by transoesophageal echocardiography (TEE).

Results: Oral anticoagulation (OAC) was prescribed in 799 (97.2\%) patients aged $\geq 65$ years and in $1054(91.8 \%)$ of those aged $<65$ years $(p<0.001)$. In patients treated with OAC, those aged $\geq 65$ years less often received vitamin $\mathrm{K}$ antagonist (VKA) (267 [33.4\%] vs. 416 [39.5\%]) and more often non-VKA-OAC (NOAC) (532 [66.6\%] vs. $638[60.5 \%], p=0.008, p=0.008$ ) compared to patients < 65 years. On TEE, LAA thrombus was more often observed in patients aged $\geq 65$ years than those aged $<65$ years (63 [7.7\%] vs. $46[4.0 \%], p<0.001)$, with an absolute but not statistically significant difference between patients aged $65-74$ and $\geq 75$ years (47 [7.3\%] vs. 16 [8.8\%], $p=0.528$ ). In patients aged $\geq 65$ years, there was no difference in the prevalence of LAA thrombus between patients treated with VKA and NOAC, in contrast to patients aged $<65$ years, in whom such a difference was observed (27 [6.5\%] vs. 16 [2.5\%], $p=0.002)$. In multivariate logistic regression, predictors of LAA thrombus in both age groups were older age, non-paroxysmal $A F$, and heart failure, whereas only in patients aged $<65$ years - VKA use, and in those aged $\geq 65$ years - lower glomerular filtration rate and platelet count.

Conclusions: Despite OAC use, older patients with AF remain at high risk of LAA thrombus formation. Older age, non-paroxysmal AF, and heart failure are predictors of LAA thrombus, irrespective of age.

Key words: thromboembolic risk, age, stroke prevention, oral anticoagulation.

\author{
Corresponding author: \\ Agnieszka Kapłon-Cieślicka, \\ $\mathrm{MD}, \mathrm{PhD}$ \\ $1^{\text {st }}$ Department of Cardiology \\ Medical University of Warsaw \\ 1a Banacha St. \\ Warsaw 02-097, Poland \\ Phone: +48225992958 \\ Fax: +48 225991957 \\ E-mail: agnieszka.kaplon@ \\ gmail.com
}


M. Gawałko, M. Budnik, B. Uziębło-Życzkowska, I. Gorczyca, P. Krzesiński, P. Scisło, J. Kochanowski, A. Michalska, O. Jelonek, K. Starzyk, A. Jurek, M. Kiliszek, B. Wożakowska-Kapłon, G. Gielerak, K.J. Filipiak, G. Opolski, A. Kapłon-Cieślicka

\section{Introduction}

Atrial fibrillation (AF) is the most commonly encountered sustained cardiac arrhythmia, and its prevalence increases sharply after 65 years of age [1]. Over $10 \%$ of individuals aged 80 years or more have AF [2]. Recent projections based on the Rotterdam study suggest that from 2015 to 2050, the number of adults aged $>75$ years with AF in the European Union will more than double, rising from 6.3 to 12.9 million [3]. The aetiology, course of illness, and thromboembolic outcomes in older patients with AF might differ from those in the younger population with AF [4]. The pathogenesis of AF in the young with structurally normal atria but electrophysiological "triggers" in the form of pulmonary vein ectopic foci is in stark contrast to that observed in older patients, who develop AF primarily due to structural abnormalities including atrial fibrosis and dilatation as well as systemic disorders such as chronic kidney disease (CKD) [5, 6]. Haemodynamic consequences of loss of atrial contraction in AF are usually more pronounced in older patients with stiffer left ventricles compared to young individuals [1]. Several structural and functional cardiac abnormalities are associated with significant left atrial appendage (LAA) stasis, which may lead to LAA thrombus formation [7]. However, it is not known whether age itself is truly associated with an increased tendency for LAA thrombi formation. Whereas some studies showed that age itself does not predict the presence of LA thrombus [8], some indicated an increased risk of LA thrombus formation with older age [9]. However, all current data are based on small numbers of patients.

In the study reported herein, we aimed to compare LAA thrombus prevalence and its predictors between old and young patients with AF.

\section{Material and methods}

\section{Study population}

This observational study, conducted in 3 high-reference cardiology departments (in an academic, military, and district hospital), included consecutive patients with AF who underwent transoesophageal echocardiography (TEE) before AF direct current cardioversion or ablation (pulmonary vein isolation) between 2014 and 2018.

The patients were divided into 2 age groups ( $<65$ and $\geq 65$ years). Then, the older group was further divided into 2 groups for an additional subanalysis (65-74 and $\geq 75$ years).

\section{Procedures and data collection}

Data (including laboratory tests and echocardiography results) were gathered retrospectively from medical records. Patients were included in the study regardless of the presence or type of anticoagulant treatment prior to TEE.

In the academic department, all patients have TEE performed routinely before direct current cardioversion of $\mathrm{AF}$ or catheter ablation for $A F$ (pulmonary vein isolation), irrespective of the presence or type of anticoagulation. The only exception are patients admitted for emergency indications [10]. In the district and military hospitals, TEE preceding AF cardioversion or ablation was performed in case of any doubt regarding the efficacy of anticoagulant treatment or patient compliance. In all departments, TEE was conducted within 48 hours prior to the scheduled procedure (usually directly or a few hours before the procedure). All TEE studies were performed by certified echocardiographers (certified with accreditation of the Section of Echocardiography of the Polish Cardiac Society), using an EPIQ 7 Ultrasound Machine ${ }^{\circledR}$ (Philips Medical Systems, Andover, Massachusetts, United States), iE33 Ultrasound Machine ${ }^{\circledR}$ (Philips Medical Systems), General Electric Vivid 7 (GE Healthcare, Milwaukee, Wisconsin, United States), or E95 Ultrasound Machine ${ }^{\circledR}$ (GE Healthcare). In cases of left atrial (LA) thrombus suspicion, the study was evaluated by a second echocardiographer, and if any doubt persisted, by a third echocardiographer, to establish the most reliable and unanimous diagnosis, and to enable safe referral for cardioversion or ablation. Written informed consent for TEE was obtained from all patients. In patients with LAA thrombus, ablation or cardioversion was postponed and an intensified anticoagulant regimen was initiated.

The study protocol was submitted to the Ethics Committee, which approved the research protocol and retrospective review of medical records. The Committee waived the requirement to obtain in formed consent from the patients.

\section{Definitions}

Chronic kidney disease was defined as abnormalities of kidney structure or function (any of the following: albuminuria [albumin excretion rate $\geq 30 \mathrm{mg} /$ day or albumin-to-creatinine ratio $\geq 30$ $\mathrm{mg} / \mathrm{g}]$, urine sediment abnormalities, electrolyte and other abnormalities due to tubular disorders, abnormalities detected by histology, structural abnormalities detected by imaging, history of kidney transplantation, glomerular filtration rate [GFR] $<60 \mathrm{ml} / \mathrm{min} / 1.73 \mathrm{~m}^{2}$ ) present for 3 or more months, with implications for health [11].

Heart failure (HF) was defined as a clinical syndrome characterised by typical symptoms (e.g. breathlessness, ankle swelling, fatigue) that may be accompanied by signs (e.g. elevated jugular venous pressure, pulmonary crackles, peripheral oedema) caused by structural and/or functional 
cardiac abnormality, resulting in reduced cardiac output and/or elevated intracardiac pressure at rest or during stress [12].

\section{Primary endpoint}

The presence of LA thrombus on TEE was deemed the primary endpoint of the study.

\section{Statistical analysis}

Data were presented as median and interquartile range, mean \pm standard deviation, or number of patients and percentages, where appropriate. Differences in medians were compared using the Kruskal-Wallis test, and differences in means were compared using Student's t-test. Frequencies of parameters or events were compared using $\chi^{2}$ test or Fisher's exact test, as appropriate. For all tests, a $p$-value $<0.05$ was considered to be statistically significant. To determine predictors of LA thrombus on TEE in both age groups, univariate and multivariate logistic regression analyses were performed. Table S I (supplementary material online) presents variables included in univariate logistic regression analyses. Only variables that were available for more than $92 \%$ of patients were included in the logistic regression analysis. The multiple logistic regression model included all variables found to be predictors of LA thrombus in univariate analyses. Statistical analysis was performed with SPSS version 15.0 (SPSS Inc., Chicago, IL, USA).

\section{Results}

A total of 1970 patients with AF were included in the study. Patients were divided into 2 groups: 1148 (58.3\%) patients aged < 65 years and 822 patients $(41.7 \%)$ aged $\geq 65$ years, including 182 patients (22.1\% of the 822 patients) aged $\geq 75$ years. Compared to the younger group, patients aged $\geq 65$ were twice more often women, and, as expected, were burdened with more concomitant diseases. Detailed clinical characteristics of both age groups are shown in Table I.

Oral anticoagulation (OAC) was prescribed in 799 (97.2\%) patients aged $\geq 65$ years compared to $1054(91.8 \%)$ in those aged $<65$ years $(p<0.001)$. Among patients treated with OAC, those aged $\geq 65$ years less often received vitamin $\mathrm{K}$ antagonist (VKA) (267 [33.4\%] vs. 416 [39.5\%]) and more often non-VKA-OAC (NOAC) (532 [66.6\%] vs. 638 [60.5\%], $p=0.008)$ compared to patients younger than 65 years. In patients receiving NOAC, patients aged $\geq 65$ years were more often prescribed reduced doses of NOAC compared to the younger group $(79$ [14.8\%] vs. 19 [3.0\%], $p<0.001)$. No significant differences in relation to antiplatelet therapy were seen between the 2 groups. Details on antithrombotic treatment in both age groups are presented in Table S II.

While comparing the 2 prespecified subgroups of older patients, those aged $\geq 75$ years were less often prescribed OAC than patients aged 65-74 years (Table S II). As shown in Figure 1, in anticoagulated patients, the frequency of VKA therapy decreased and the frequency of NOAC therapy (in particular with rivaroxaban and apixaban) increased after the age of 75 years. Reduced doses of NOAC were used in $53(38.1 \%)$ patients aged $\geq 75$ years, and in 26 (6.6\%) of those aged 65-74 years $(p<0.001)$, as shown in Table S II (supplementary material online). The appropriate reduced doses were prescribed to 24 (68.6\%), 23 (57.5\%), and $4(100 \%)$ patients in the dabigatran, rivaroxaban, and apixaban groups, respectively (Table S III [supplementary material online])

On TEE, LA thrombi were detected in 109 (5.5\%) patients. All of those thrombi were found in LAA. The frequency of LAA thrombus was higher in patients $\geq 65$ years compared to those $<65$ years (63 [7.7\%] vs. 46 [4.0\%], $p<0.001$; as shown in Table II). There was an absolute, although statistically insignificant, difference in LAA thrombus prevalence between patients aged $65-74$ years and $\geq 75$ years (47 [7.3\%] vs. 16 [8.8\%], $p=0.528$; as shown in Table S IV [supplementary material online]). In patients aged $\geq 65$ years, there was no statistically significant difference in the frequency of LAA thrombus between patients treated with VKA and NOAC, in contrast to patients aged < 65 years, in whom NOAC treatment was associated with significantly lower LAA thrombus prevalence, as presented in Table III and Figure 2.

In multivariate logistic regression, predictors of LAA thrombus in patients aged $\geq 65$ years were: older age, non-paroxysmal AF (vs. paroxysmal AF), $\mathrm{HF}$, and lower GFR and platelet count (as shown in Table IV), whereas in patients aged $<65$ years - older age, non-paroxysmal AF (vs. paroxysmal $A F), H F$, and VKA use (compared to NOAC therapy), as shown in Table $V$. In patients aged $\geq 65$ years, no type of OAC treatment (VKA vs. NOAC; reduced doses of NOAC) predicted LAA thrombus.

Despite the fact that HF appeared to be a significant predictor of LAA thrombus in both age groups, no statistically significant differences were observed between patients aged $<65$ years and those aged $\geq 65$ years according to ejection fraction (57 [45-60] vs. 57 [50-60], $p=$ 0.96), LA diameter (45 [41-49] vs. 45 [41-48], $p=0.19)$, and left ventricular diastolic dimension (53 [49-57] vs. 52 [47-57], $p=0.08$ ) (Table II) as well as between patients those aged 65-74 and $\geq 75$ - ejection fraction (58 [50-60] vs. 55 [50-60], $p=0.19$ ), LA diameter (45 [42-48] vs. 46 [42-51], $p=0.20)$, and left ventricular diastolic dimension (52 [47-57] vs. 50 [46-57], $p=0.65$ ) (Table S IV). 
M. Gawałko, M. Budnik, B. Uziębło-Życzkowska, I. Gorczyca, P. Krzesiński, P. Scisło, J. Kochanowski, A. Michalska, O. Jelonek, K. Starzyk, A. Jurek, M. Kiliszek, B. Wożakowska-Kapłon, G. Gielerak, K.J. Filipiak, G. Opolski, A. Kapłon-Cieślicka

Table I. Clinical characteristics, thromboembolic, and bleeding risk in patients aged less than 65 compared to patients aged 65 years and older.

\begin{tabular}{|c|c|c|c|}
\hline Variable & $\begin{array}{l}\text { Patients aged }<65 \text { years } \\
\qquad(n=1148)\end{array}$ & $\begin{array}{l}\text { Patients aged } \geq 65 \text { years } \\
\qquad(n=822)\end{array}$ & $p$-value \\
\hline Age [years] & 57 [49-61] & 69 [67-74] & $<0.01$ \\
\hline Female $[n(\%)]$ & $294(26 \%)$ & $423(52 \%)$ & $<0.01$ \\
\hline $\mathrm{BMI}\left[\mathrm{kg} / \mathrm{m}^{2}\right]$ & $\begin{array}{c}29[26-32] \\
n=944\end{array}$ & $\begin{array}{c}28[26-32] \\
n=581\end{array}$ & $<0.01$ \\
\hline Obesity $[n,(\%)]$ & $\begin{array}{c}414(42 \%) \\
n=984\end{array}$ & $\begin{array}{c}222(36 \%) \\
n=617\end{array}$ & $<0.01$ \\
\hline \multicolumn{4}{|l|}{ Type of AF $[n(\%)]$} \\
\hline Paroxysmal AF & $613(53 \%)$ & 333 (41\%) & $<0.01$ \\
\hline Non-paroxysmal AF & $535(47 \%)$ & $489(59 \%)$ & $<0.01$ \\
\hline \multicolumn{4}{|l|}{ Type of procedure planned [ $n(\%)]$} \\
\hline Cardioversion & $317(28 \%)$ & $421(51 \%)$ & $<0.01$ \\
\hline Ablation & $831(72 \%)$ & $401(49 \%)$ & $<0.01$ \\
\hline \multicolumn{4}{|l|}{ Concomitant diseases $[n(\%)]$} \\
\hline Diabetes & 154 (13\%) & $212(26 \%)$ & $<0.01$ \\
\hline CAD & $137(12 \%)$ & $225(27 \%)$ & $<0.01$ \\
\hline Previous myocardial infarction & $52(4.5 \%)$ & $94(11 \%)$ & $<0.01$ \\
\hline Previous $\mathrm{PCl} / \mathrm{CABG}$ & $60(5.2 \%)$ & $104(13 \%)$ & $<0.01$ \\
\hline PAD & $\begin{array}{c}12(1.3 \%) \\
n=896\end{array}$ & $\begin{array}{c}33(5.8 \%) \\
n=569\end{array}$ & $<0.01$ \\
\hline Vascular disease (CAD and/or PAD) & $149(13 \%)$ & $249(30 \%)$ & $<0.01$ \\
\hline Heart failure & $182(16 \%)$ & $226(27 \%)$ & $<0.01$ \\
\hline Previous stroke/TIA/peripheral embolism & $54(4.7 \%)$ & $84(10 \%)$ & $<0.01$ \\
\hline Chronic respiratory disease & $\begin{array}{c}40(4.5 \%) \\
n=895\end{array}$ & $\begin{array}{c}48(8.4 \%) \\
n=569\end{array}$ & 0.01 \\
\hline Chronic kidney disease & $64(5.6 \%)$ & $130(16 \%)$ & $<0.01$ \\
\hline Liver disease & $\begin{array}{c}16(1.8 \%) \\
n=896\end{array}$ & $\begin{array}{l}6(1.1 \%) \\
n=569\end{array}$ & 0.20 \\
\hline Hyperthyroidism & $99(8.6 \%)$ & $59(7.2 \%)$ & 0.27 \\
\hline Hypothyroidism & $82(7.1 \%)$ & $110(13 \%)$ & $<0.01$ \\
\hline Malignancy & $\begin{array}{c}29(3.7 \%) \\
n=789\end{array}$ & $\begin{array}{c}38(9.2 \%) \\
n=413\end{array}$ & 0.02 \\
\hline Previous bleeding & $41(3.6 \%)$ & $60(7.3 \%)$ & $<0.01$ \\
\hline Labile INR & $\begin{array}{l}8(0.9 \%) \\
n=896\end{array}$ & $\begin{array}{c}10(1.8 \%) \\
n=569\end{array}$ & 0.24 \\
\hline Smoking & $\begin{array}{c}278(35 \%) \\
n=786\end{array}$ & $\begin{array}{c}101(25 \%) \\
n=411\end{array}$ & $<0.01$ \\
\hline \multicolumn{4}{|l|}{ Thromboembolic and bleeding risk } \\
\hline $\mathrm{CHADS}_{2}$ score & $1[0-1]$ & $2[1-2]$ & $<0.01$ \\
\hline $\mathrm{CHA}_{2} \mathrm{DS}_{2}$-VASc score & $1[1-2]$ & $3[3-4]$ & $<0.01$ \\
\hline HAS-BLED score & $\begin{array}{l}1[0-1] \\
n=896\end{array}$ & $\begin{array}{l}2[2-3] \\
n=569\end{array}$ & $<0.01$ \\
\hline
\end{tabular}

$A F$ - atrial fibrillation, $B M I$ - body mass index, $C A B G$ - coronary artery bypass graft, $C A D$ - coronary artery disease, $P A D$ - peripheral artery disease, $\mathrm{PCl}$ - percutaneous coronary intervention, TIA - transient ischaemic attack. 


\section{Discussion}

The major findings of the present study are as follows. First, despite OAC use in most, older patients with AF remain at high risk of LAA thrombus formation. Second, in both age groups, older age, non-paroxysmal AF (vs. paroxysmal AF), and HF proved to be strong predictors of LAA thrombus. Third, in the older patients, age and GFR were related to the risk of thrombus formation. Last, in patients aged $<65$ years, NOAC treatment was associated with a lower risk of LAA thrombus compared to VKA therapy.

The attributable risk of thromboembolic events increases sharply with age, from $1.5 \%$ for patients aged 50 to 59 years to $23.5 \%$ for patients aged 80 to 89 years, and with $40 \%$ of stroke in those $>80$ years due to AF [13]. In a sub-analysis of the PREFER in AF (PREvention of Thromboembol-

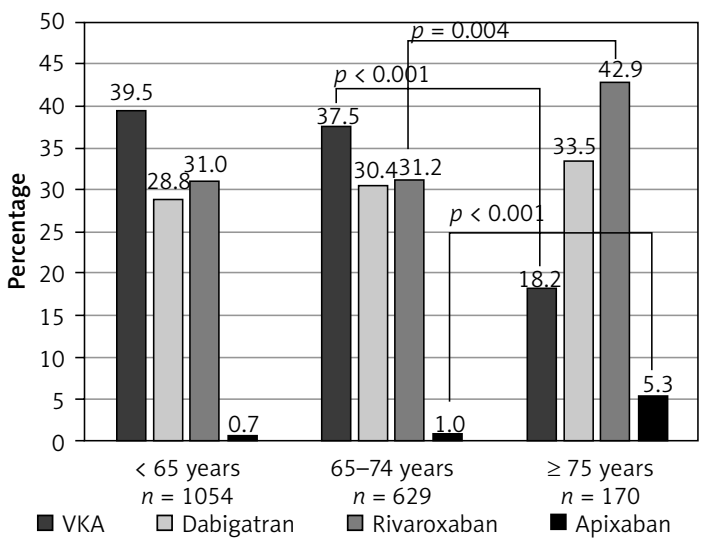

Figure 1. Type of treatment in anticoagulated patients $(n=1853)$ in relation to age

VKA - vitamin $K$ antagonist. For pairwise comparisons between groups $(<65$ years vs. 65-74 years, and 65-74 years $v s . \geq 75$ years), only $p$ values of $<0.05$ are given.

Table II. Laboratory and echocardiographic characteristics of patients aged less than 65 years compared to patients aged 65 years and older

\begin{tabular}{|c|c|c|c|}
\hline Variable & $\begin{array}{l}\text { Patients aged < } 65 \text { years } \\
\qquad(n=1148)\end{array}$ & $\begin{array}{l}\text { Patients aged } \geq 65 \\
\text { years }(n=822)\end{array}$ & $p$-value \\
\hline \multicolumn{4}{|l|}{ Laboratory parameters } \\
\hline Haemoglobin [g/dl] & $\begin{array}{c}15[14-16] \\
n=1132\end{array}$ & $\begin{array}{c}14[13-15] \\
n=801\end{array}$ & $<0.01$ \\
\hline Haematocrit [\%] & $\begin{array}{c}43[41-46] \\
n=999\end{array}$ & $\begin{array}{c}41[39-44] \\
n=643\end{array}$ & $<0.01$ \\
\hline $\mathrm{WBC}[\mathrm{K} / \mu \mathrm{l}]$ & $\begin{array}{c}7.4[6.3-8.8] \\
n=1058\end{array}$ & $\begin{array}{c}7.3[6.1-8.5] \\
n=682\end{array}$ & 0.03 \\
\hline Platelet count $[\mathrm{K} / \mu \mathrm{l}]$ & $\begin{array}{c}219[185-252] \\
n=1132\end{array}$ & $\begin{array}{c}210[174-252] \\
n=795\end{array}$ & 0.01 \\
\hline GFR $\left[\mathrm{ml} / \mathrm{min} / 1.73 \mathrm{~m}^{2}\right]$ & $\begin{array}{l}79[65-90] \\
n=1035\end{array}$ & $\begin{array}{c}65[53-89] \\
n=818\end{array}$ & $<0.01$ \\
\hline AST [U/I] & $\begin{array}{c}24[20-30] \\
n=865\end{array}$ & $\begin{array}{c}24[20-29] \\
n=553\end{array}$ & 0.21 \\
\hline $\mathrm{ALT}[\mathrm{U} / \mathrm{l}]$ & $\begin{array}{c}32[24-43] \\
n=873\end{array}$ & $\begin{array}{l}25[19-35] \\
n=554\end{array}$ & $<0.01$ \\
\hline INR (in patients on VKA) & $\begin{array}{c}1.2[1.0-2.1] \\
n=384\end{array}$ & $\begin{array}{c}1.4[1.1-2.2] \\
n=235\end{array}$ & $<0.01$ \\
\hline \multicolumn{4}{|l|}{ Transthoracic echocardiography* } \\
\hline Ejection fraction [\%] & $\begin{array}{c}57[45-60] \\
n=418\end{array}$ & $\begin{array}{c}57[50-60] \\
n=409\end{array}$ & 0.96 \\
\hline Left atrial diameter [mm] & $\begin{array}{c}45[41-49] \\
n=512\end{array}$ & $\begin{array}{c}45[41-48] \\
n=376\end{array}$ & 0.19 \\
\hline Left ventricular diastolic diameter [mm] & $\begin{array}{c}53[49-57] \\
n=302\end{array}$ & $\begin{array}{c}52[47-57] \\
n=296\end{array}$ & 0.08 \\
\hline \multicolumn{4}{|l|}{ Transoesophageal echocardiography* } \\
\hline Thrombus $[n(\%)]$ & $46(4.0 \%)$ & $63(7.7 \%)$ & $<0.01$ \\
\hline LAA emptying velocity $[\mathrm{cm} / \mathrm{s}]$ & $\begin{array}{c}52[34-76] \\
n=925\end{array}$ & $\begin{array}{c}40[27-60] \\
n=556\end{array}$ & $<0.01$ \\
\hline $\operatorname{SEC}[n(\%)]$ & $187(19 \%)$ & $154(24 \%)$ & 0.17 \\
\hline
\end{tabular}

* - performed during index hospitalisation, ALT - alanine transaminase, AST - aspartate transaminase, GFR - glomerular filtration rate, INR - international normalised ratio, LAA - left atrial appendage, SEC - spontaneous echo contrast, WBC - white blood cells. 
M. Gawałko, M. Budnik, B. Uziębło-Życzkowska, I. Gorczyca, P. Krzesiński, P. Scisło, J. Kochanowski, A. Michalska, O. Jelonek, K. Starzyk, A. Jurek, M. Kiliszek, B. Wożakowska-Kapłon, G. Gielerak, K.J. Filipiak, G. Opolski, A. Kapłon-Cieślicka

Table III. Comparison of patients on different anticoagulant regimens in relation to age

\begin{tabular}{|c|c|c|c|c|c|c|}
\hline \multirow[t]{2}{*}{ Variable } & \multicolumn{3}{|c|}{ Patients aged $<65$ years } & \multicolumn{3}{|c|}{ Patients aged $\geq 65$ years } \\
\hline & $\begin{array}{c}\text { VKA } \\
(n=416)\end{array}$ & $\begin{array}{c}\text { NOAC } \\
(n=638)\end{array}$ & $p$-value & $\begin{array}{c}\text { VKA } \\
(n=267)\end{array}$ & $\begin{array}{c}\text { NOAC } \\
(n=532)\end{array}$ & $p$-value \\
\hline Age [years] & $58[52-61]$ & $58[52-64]$ & 0.59 & $69[67-72]$ & $70[67-75]$ & $<0.01$ \\
\hline Female $[n(\%)]$ & $100(24 \%)$ & $170(27 \%)$ & 0.35 & $138(52 \%)$ & $274(52 \%)$ & 1.00 \\
\hline Paroxysmal AF [n (\%)] & $236(57 \%)$ & $298(47 \%)$ & $<0.01$ & $146(55 \%)$ & $169(32 \%)$ & $<0.01$ \\
\hline Non-paroxysmal AF $[n(\%)]$ & $180(43 \%)$ & $340(53 \%)$ & $<0.01$ & $121(45 \%)$ & $363(68 \%)$ & $<0.01$ \\
\hline $\begin{array}{l}\text { Previous ischaemic stroke/TIA/ } \\
\text { peripheral embolism }[n(\%)]\end{array}$ & $17(4.1 \%)$ & $37(5.8 \%)$ & 0.25 & $31(12 \%)$ & $49(9.2 \%)$ & 0.32 \\
\hline Previous bleeding $[n(\%)]$ & $13(3.1 \%)$ & $24(3.8 \%)$ & 0.61 & $11(4.1 \%)$ & $45(8.5 \%)$ & 0.03 \\
\hline \multicolumn{7}{|l|}{ Thromboembolic and bleeding risk } \\
\hline $\mathrm{CHADS}_{2}$ score & $1[1-2]$ & $1[0-1]$ & 0.08 & $1[1-2]$ & $2[1-3]$ & 0.09 \\
\hline $\mathrm{CHA}_{2} \mathrm{DS}_{2}-\mathrm{VASc}$ score & $1[1-2]$ & $1[1-2]$ & 0.15 & $3[2.5-4]$ & $3[3-5]$ & 0.28 \\
\hline HAS-BLED score & $\begin{array}{l}1[0-1] \\
n=337\end{array}$ & $\begin{array}{l}1[0-1] \\
n=465\end{array}$ & 0.31 & $\begin{array}{l}2[2-2] \\
n=187\end{array}$ & $\begin{array}{l}2[2-3] \\
n=359\end{array}$ & 0.31 \\
\hline \multicolumn{7}{|c|}{ Transoesophageal echocardiography* } \\
\hline Thrombus $[n(\%)]$ & $27(6.5 \%)$ & $16(2.5 \%)$ & $<0.01$ & $25(9.4 \%)$ & $35(6.6 \%)$ & 0.20 \\
\hline LAA emptying velocity $[\mathrm{cm} / \mathrm{s}]$ & $\begin{array}{c}54[32-75] \\
n=367\end{array}$ & $\begin{array}{c}50[33-72] \\
n=467\end{array}$ & 0.64 & $\begin{array}{c}47[30-67] \\
n=224\end{array}$ & $\begin{array}{c}36[25-56] \\
n=310\end{array}$ & $<0.01$ \\
\hline $\operatorname{SEC}[n(\%)]$ & $\begin{array}{c}81(21 \%) \\
n=387\end{array}$ & $\begin{array}{c}100(19 \%) \\
n=525\end{array}$ & 0.11 & $\begin{array}{l}52(22 \%) \\
n=235\end{array}$ & $\begin{array}{l}99(26 \%) \\
n=386\end{array}$ & 0.77 \\
\hline
\end{tabular}

* - performed during index hospitalisation, AF - atrial fibrillation, LAA - left atrial appendage, NOAC - non-vitamin $K$ antagonist oral anticoagulants, SEC - spontaneous echo contrast, TIA - transient ischaemic attack, VKA - vitamin K antagonists.

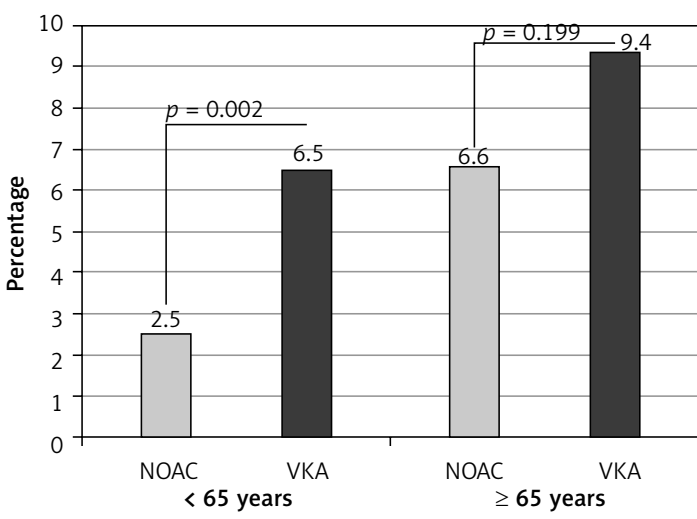

Figure 2. Prevalence of left atrial appendage thrombus in relation to age and type of anticoagulation

NOAC - non-vitamin $K$ antagonist oral anticoagulants, VKA - vitamin $K$ antagonists. ic Events-European Registry in Atrial Fibrillation) study, the prevalence of thromboembolic events was $4.3 \%$ per year in AF patients over 85 years old and $2.3 \%$ per year in patients with AF who were younger than 85 years, despite antithrombotic treatment [14]. In a meta-analysis including 8932 patients from 12 randomised trials on stroke prevention in $A F$, the risk of ischaemic stroke increased by age, with a $45 \%$ increase in risk for every 10 years starting at the age of 50 years [15].

Historically, the risk of thromboembolism has been considered to be independent of the AF pattern [16-19]. This consensus of risk equivalence between AF types is reflected in current North American [17] and European AF guidelines [16]. However, recent reports suggest that the pattern of $A F$ is a strong predictor of stroke, and division

Table IV. Logistic regression analyses of predictors of left atrial thrombus in the group of patients aged 65 years or older

\begin{tabular}{|c|c|c|c|c|}
\hline \multirow[t]{2}{*}{ Variable } & \multirow{2}{*}{$\begin{array}{l}\text { Univariate } \\
\text { analysis }\end{array}$} & \multicolumn{3}{|c|}{ Multivariate analysis } \\
\hline & & OR & $95 \% \mathrm{Cl}$ & $p$-value \\
\hline Age (every 10 years) & 0.03 & 0.97 & $0.95-0.99$ & $<0.01$ \\
\hline Non-paroxysmal AF (vs. paroxysmal AF) & $<0.01$ & 3.78 & $1.79-8.00$ & $<0.01$ \\
\hline Heart failure & $<0.01$ & 2.27 & $1.30-3.97$ & $<0.01$ \\
\hline Haemoglobin (every $5 \mathrm{~g} / \mathrm{dL}$ ) & $<0.05$ & 1.07 & $0.97-1.19$ & 0.15 \\
\hline Platelet count (every $60,000 / \mu \mathrm{m}$ ) & 0.02 & 0.99 & $0.989-0.999$ & 0.02 \\
\hline GFR (every $10 \mathrm{ml} / \mathrm{min} / 1.73 \mathrm{~m}^{2}$ ) & 0.02 & 0.98 & $0.97-0.99$ & 0.03 \\
\hline
\end{tabular}

AF - atrial fibrillation, GFR - glomerular filtration rate. 
Table V. Logistic regression analyses of predictors of left atrial thrombus in patients aged less than 65 years

\begin{tabular}{|lcccc|}
\hline Variable & Univariate & \multicolumn{3}{c|}{ Multivariate analysis } \\
\cline { 3 - 5 } & & Onalysis & $95 \% \mathrm{Cl}$ & $p$-value \\
\hline Age (every 10 years) & $<0.01$ & 1.32 & $1.01-1.72$ & 0.43 \\
\hline Non-paroxysmal AF (vs. paroxysmal AF) & $<0.01$ & 6.54 & $2.66-16.04$ & $<0.01$ \\
\hline Diabetes & 0.01 & 1.76 & $0.84-3.71$ & 0.14 \\
\hline Vascular disease (CAD and/or PAD) & $<0.01$ & 0.78 & $0.33-1.84$ & 0.57 \\
\hline Heart failure & $<0.01$ & 2.20 & $1.11-4.36$ & 0.02 \\
\hline VKA (vs. NOAC) & $<0.01$ & 3.22 & $1.67-6.18$ & $<0.01$ \\
\hline AF- atrial fibrillation, CAD - coronary artery disease, NOAC - non-vitamin K antagonist oral anticoagulants, VKA - vitamin K antagonists.
\end{tabular}

of $A F$ into paroxysmal and non-paroxysmal $A F$ is gaining widespread acceptance in clinical practice. In the study by Vanassche et al., the annual rate of thromboembolism increased from $2.1 \%$ in paroxysmal AF to $3.0 \%$ in persistent and $4.2 \%$ in permanent $A F$, resulting in a hazard ratio for non-paroxysmal vs. paroxysmal of 1.91 (95\% confidence interval $[\mathrm{Cl}] 1.50-2.43 ; p<0.001)[20]$. A recent meta-analysis by Ganesan et al., including almost 100,000 patients, reported a $38 \%$ greater risk of thromboembolism and a $22 \%$ increase in mortality in non-paroxysmal AF as compared to paroxysmal AF [21]. Whether AF type is indeed an independent risk factor for stroke or rather a reflection of patients' thromboembolic risk profile is yet to be determined.

$\mathrm{HF}$ is a well-recognised predictor of stroke in patients with AF [22-25]. In our study, HF was associated with more than doubled risk of LAA thrombus in both age groups. Similarly to AF, HF is a growing epidemic and its prevalence increases with age [26]. When present in combination, AF and $\mathrm{HF}$ portend a worse prognosis than either condition alone, with a 4-fold increased risk of systemic thromboembolism events per year [27]. Moreover, $\mathrm{HF}$ is a negative predictor of LAA thrombus resolution in patients with AF receiving OAC [23].

Another factor related to increased risk of LAA thrombus in our study was lower GFR. Patients with advanced kidney disease are known to be at increased bleeding risk (Piccini et al., 2013; Singer et al., 2013). In both the AnTicoagulation and Risk factors In AF (ATRIA) study [28] and the $\mathrm{R}_{2} \mathrm{CHADS}_{2}$ score [29], renal dysfunction defined as GFR $<45$ $\mathrm{ml} / \mathrm{min} / 1.73 \mathrm{~m}^{2}$ and $<60 \mathrm{ml} / \mathrm{min} / 1.73 \mathrm{~m}^{2}$, respectively, was related to higher thromboembolic risk and enhanced its stratification compared to the $\mathrm{CHA}_{2} \mathrm{DS}_{2}$-VASc and $\mathrm{CHADS}_{2}$ scores. Recently, we proposed a new cut-off of $56 \mathrm{ml} / \mathrm{min} / 1.73 \mathrm{~m}^{2}$ for an improved thrombus risk stratification in $\mathrm{AF}$ [22]. The lack of association between GFR and the presence of LAA thrombus in patients younger than 65 years in our study was probably due to the low prevalence of renal dysfunction in these patients.
In our study, the older the patient, the higher the risk for LAA thrombus formation (a known observation reflected in the $\mathrm{CHA}_{2} \mathrm{DS}_{2}$-VASc score), and this rule applies even among patients younger than 65 years. In the Framingham Study, the percentage of stroke attributable to AF increased steeply, from $1.5 \%$ at $50-59$ years of age, through $2.8 \%$ at age $60-69$ years and $9.9 \%$ at $70-79$ years, to $23.5 \%$ at $80-89$ years of age [30]. The findings of the above and further studies showed that octogenarian would be burdened with a substantially higher thromboembolic risk than for a 70-yearold patient $[13,14]$. In our study, the prevalence of LAA thrombus in patients aged 75 years and older was higher than in patients aged $65-74$ years (8.8\% vs. $7.3 \%)$, although the difference was not statistically significant, which might have been related to a low number of patients $\geq 75$ years.

Among physicians, the most commonly reported concern with anticoagulation is the fear of falls and consequent bleeding [31]. This has resulted in OAC underuse, especially in older patients $[32,33]$. However, more recently, there has been a progressive increase in the proportion of older patients with AF receiving guideline-recommended therapy. In the Prevention of Thromboembolic Events-European Registry in AF_65 years) [34]. In the Global Anticoagulant Registry in the FIELD-AF (GARFIELD-AF), OAC use increased from 55 to $74 \%$ during 5-year observation from 2011 to 2016. Of particular relevance to older patients, the mean age in this study was 75 years, with $87 \%$ of patients being aged 65 years or older [35]. This positive trend is also reflected in our study, with $97.2 \%$ of patients aged $\geq 65$ years receiving OAC. Still, there were significant differences in the frequency of OAC use between patients from different age groups. While lower frequency of OAC use in patients < 65 years of age $(91.8 \%)$ as compared to patients aged $65-74$ years $(98.3 \%)$ may be explained by their lower $\mathrm{CHA}_{2} \mathrm{DS}_{2}$-VASc score (with a median score of 1 point, which is a class Ila indication to OAC), lower frequency of OAC use in patients aged $\geq 75$ years (93.4\%) suggests therapeutic inertia, given that there was no difference 
M. Gawałko, M. Budnik, B. Uziębło-Życzkowska, I. Gorczyca, P. Krzesiński, P. Scisło, J. Kochanowski, A. Michalska, O. Jelonek, K. Starzyk, A. Jurek, M. Kiliszek, B. Wożakowska-Kapłon, G. Gielerak, K.J. Filipiak, G. Opolski, A. Kapłon-Cieślicka

in the prevalence of history of bleeding between the 2 older groups.

In landmark clinical trials, NOACs have consistently demonstrated to be associated with lower rates of intracranial haemorrhage compared with VKA [36-39]. In ARISTOTLE, apixaban was also reported to cause major bleeding less often than warfarin [40]. These aspects may explain the preference for the prescription of NOAC among patients aged $\geq 65$ years in our study, especially apixaban among the oldest age group ( $>75$ years).

There is also growing evidence of a possible reduction of thromboembolic risk of NOAC compared to VKA [38, 41, 42]. Recent meta-analyses demonstrated similar or improved efficacy in thromboembolism prevention for NOAC compared to VKA [43-45]. This also reflected in older patients with $\mathrm{AF}[44,45]$. In our study, NOAC treatment was shown to be associated with lower risk of LAA thrombus as compared to VKA therapy in patients younger than 65 years. Notably, one third of patients on VKA with known international normalised ratio were under-anticoagulated, with an international normalised ratio below 2 . In the older ( $\geq 65$ years) group, LAA thrombus prevalence was also lower in patients receiving NOAC (6.6\%) compared to VKA-treated patients (9.4\%), although the difference did not reach statistical significance, possibly due to the smaller sample size but perhaps also due to substantially increased thrombotic risk in the older group.

Our study has several limitations. Firstly, because this study was based on retrospective data collection, some variables were not available for all the patients, as indicated in the tables. Secondly, inclusion of patients with AF routinely referred for TEE enabled assessment of the presence of LAA thrombus but limited the study group to patients scheduled for cardioversion or ablation, who are younger and at lower thromboembolic risk than the population with AF in general; hence, there is a high risk that patients with chronic AF might not be included. Therefore, there should be caution in generalising our findings to all patients with $A F$, because results may differ in other patient populations. Thirdly, the limitation of our study is also the fact that our study included only patients with AF who were qualified for ablation or cardioversion. This means that our study did not include a large group of elderly patients with AF who simply were not qualified for ablation or cardioversion, because they were too old and/or had a higher comorbidity burden. So, in fact, the results of this analysis cannot be simply extrapolated to the entire population of older patients with AF. Fourthly, all the results may be biased due to their observational nature. Finally, this was not a randomised controlled study comparing NOAC with VKA, and thus no ultimate conclusion on the relative efficacy of either $\mathrm{OAC}$ regimen can be drawn from our analysis.

In conclusion, despite the use of OAC, older patients with AF remain at high risk of LAA thrombus formation. Age, and non-paroxysmal AF and $\mathrm{HF}$ are predictors of LAA thrombus, irrespective of age. In the older patients, impaired kidney function and older age are also associated with higher presence of LAA thrombi.

\section{Acknowledgments}

The authors thank Paweł Piłkowski for his assistance in statistical analysis, and students (Aldona Babiarz, Aleksandra Bodys, Robert Uliński, Maciej Żochowski) for their assistance in data collection.

Monika Gawatko declares that she has no conflict of interest in relation to this publication. Monika Budnik declares that she has no conflict of interest in relation to this publication. Beata Uziębło-Życzkowska declares that she has no conflict of interest in relation to this publication. Iwona Gorczyca received a honorarium for lectures from Bayer, Boehringer Ingelheim. Paweł Krzesiński declares that he has no conflict of interest in relation to this publication. Piotr Scisto declares that he has no conflict of interest in relation to this publication. Janusz Kochanowski declares that he has no conflict of interest in relation to this publication. Anna Michalska declares that she has no conflict of interest in relation to this publication. Olga Jelonek declares that she has no conflict of interest in relation to this publication. Katarzyna Starzyk declares that she has no conflict of interest in relation to this publication. Agnieszka Jurek declares that she has no conflict of interest in relation to this publication. Marek Kiliszek declares that he has no conflict of interest in relation to this publication. Beata Wożakowska-Kapłon received honorarium for lectures from Bayer, Boehringer Ingelheim, Pfeizer. Grzegorz Gielerak declares that he has no conflict of interest in relation to this publication. Krzysztof J. Filipiak received honorarium for lectures from Bayer, Boehringer Ingelheim, MSD, Pfeizer. Grzegorz Opolski received honorarium for lectures from Bayer, Boehringer Ingelheim, Pfeizer. Agnieszka Kapłon-Cieślicka received honorarium for lectures/travel grants from Bayer, Boehringer Ingelheim, MSD, Pfeizer.

The study protocol was submitted to the Ethics Committee, which approved the research protocol and retrospective review of medical records.

The Committee waived the requirement to obtain informed consent from the patients.

\section{References}

1. Levy S. Atrial fibrillation, the arrhythmia of the elderly, causes and associated conditions. Anadolu Kardiyol Derg 2002; 2: 55-60. 
2. Fitzmaurice DA, Hobbs FD. Research into practice: management of atrial fibrillation in general practice. $\mathrm{Br}$ Gen Pract 2014; 64: 540-2.

3. Krijthe BP, Kunst A, Benjamin EJ, et al. Projections on the number of individuals with atrial fibrillation in the European Union, from 2000 to 2060. Eur Heart J 2013; 34: 2746-51.

4. Pobrotyn P, Suslo R, Witczak IT, Rypicz L, Drobnik J. An analysis of the costs of treating aged patients in a large clinical hospital in Poland under the pressure of recent demographic trends. Arch Med Sci 2020; 16: 666-71.

5. Sankaranarayanan R, Kirkwood G, Dibb K, Garratt CJ. Comparison of atrial fibrillation in the young versus that in the elderly: a review. Cardiol Res Pract 2013; 2013: 976976.

6. Domienik-Karlowicz J, Tronina O, Lisik W, Durlik M, Pruszczyk P. The use of anticoagulants in chronic kidney disease: Common point of view of cardiologists and nephrologists. Cardiol J 2020; 27: 868-74.

7. Regazzoli D, Ancona F, Trevisi N, et al. Left atrial appendage: physiology, pathology, and role as a therapeutic target. Biomed Res Int 2015; 2015: 205013.

8. Mazouz B, Keren A, Chenzbraun A. Age alone is not a risk factor for left atrial thrombus in atrial fibrillation. Heart 2008; 94: 197-9.

9. Rader VJ, Khumri TM, Idupulapati M, Stoner CN, Magalski A, Main ML. Clinical predictors of left atrial thrombus and spontaneous echocardiographic contrast in patients with atrial fibrillation. J Am Soc Echocardiogr 2007; 20: 1181-5.

10. Gawalko M, Kaplon-Cieslicka A, Budnik M, et al. Comparison of different oral anticoagulant regimens in patients with atrial fibrillation undergoing ablation or cardioversion. Pol Arch Intern Med 2017; 127: 823-31.

11. Inker LA, Astor BC, Fox CH, et al. KDOQI US commentary on the 2012 KDIGO clinical practice guideline for the evaluation and management of CKD. Am J Kidney Dis 2014; 63: 713-35.

12. Ponikowski P, Voors AA, Anker SD, et al. 2016 ESC Guidelines for the diagnosis and treatment of acute and chronic heart failure: the task force for the diagnosis and treatment of acute and chronic heart failure of the European Society of Cardiology (ESC). Developed with the special contribution of the Heart Failure Association (HFA) of the ESC. Eur J Heart Fail 2016; 18: 891-975.

13. Mitrousi K, Lip GYH, Apostolakis S. Age as a risk factor for stroke in atrial fibrillation patients: implications in thromboprophylaxis in the era of novel oral anticoagulants. J Atr Fibrillation 2013; 6: 783.

14. Patti G, Pecen L, Lucerna M, et al. Outcomes of anticoagulated patients with atrial fibrillation treated with or without antiplatelet therapy - a pooled analysis from the PREFER in AF and PREFER in AF PROLONGATON registries. Int J Cardiol 2018; 270: 160-6.

15. van Walraven C, Hart RG, Connolly S, et al. Effect of age on stroke prevention therapy in patients with atrial fibrillation: the atrial fibrillation investigators. Stroke 2009; 40: 1410-6.

16. Camm AJ, Kirchhof P, Lip GY, et al. Guidelines for the management of atrial fibrillation: the task force for the management of atrial fibrillation of the European Society of Cardiology (ESC). Europace 2010; 12: 1360-420.

17. January CT, Wann LS, Calkins H, et al. 2019 AHA/ACC/ HRS focused update of the 2014 AHA/ACC/HRS guideline for the management of patients with atrial fibrillation: a report of the American College of Cardiology/ American Heart Association task force on clinical prac- tice guidelines and the Heart Rhythm Society. J Am Coll Cardiol 2019; 74: 104-32.

18. Hohnloser SH, Pajitnev D, Pogue J, et al. Incidence of stroke in paroxysmal versus sustained atrial fibrillation in patients taking oral anticoagulation or combined antiplatelet therapy: an ACTIVE W Substudy. J Am Coll Cardiol 2007; 50: 2156-61.

19. Hart RG, Pearce LA, Rothbart RM, McAnulty JH, Asinger RW, Halperin JL. Stroke with intermittent atrial fibrillation: incidence and predictors during aspirin therapy. Stroke prevention in atrial fibrillation investigators. J Am Coll Cardiol 2000; 35: 183-7.

20. Vanassche T, Lauw MN, Eikelboom JW, et al. Risk of ischaemic stroke according to pattern of atrial fibrillation: analysis of 6563 aspirin-treated patients in ACTIVE-A and AVERROES. Eur Heart J 2015; 36: 281-7a.

21. Ganesan AN, Chew DP, Hartshorne T, et al. The impact of atrial fibrillation type on the risk of thromboembolism, mortality, and bleeding: a systematic review and meta-analysis. Eur Heart J 2016; 37: 1591-602.

22. Kaplon-Cieslicka A, Budnik M, Gawalko M, et al. Atrial fibrillation type and renal dysfunction as important predictors of left atrial thrombus. Heart 2019; 105: 1310-5.

23. Kowalczyk E, Kasprzak JD, Lipiec P. Heart failure as an independent predictor of thrombus persistence in nonvalvular atrial fibrillation: a transesophageal echocardiography-based study. Pol Arch Med Wewn 2015; 125: 358-62.

24. Inoue K, Suna S, Iwakura K, et al. Outcomes for atrial fibrillation patients with silent left atrial thrombi detected by transesophageal echocardiography. Am J Cardiol 2017; 120: 940-6.

25. Wu MS, Gabriels J, Khan M, et al. Left atrial thrombus despite continuous direct oral anticoagulant or warfarin therapy in patients with atrial fibrillation: insights into rates and timing of thrombus resolution. J Interv Card Electrophysiol 2018; 53: 159-67.

26. Pulignano G, Del Sindaco D, Di Lenarda A, et al. Incremental value of gait speed in predicting prognosis of older adults with heart failure: insights from the IMAGE-HF study. JACC Heart Fail 2016; 4: 289-98.

27. Mountantonakis SE, Grau-Sepulveda MV, Bhatt DL, Hernandez AF, Peterson ED, Fonarow GC. Presence of atrial fibrillation is independently associated with adverse outcomes in patients hospitalized with heart failure: an analysis of get with the guidelines-heart failure. Circ Heart Fail 2012; 5: 191-201.

28. Singer DE, Chang Y, Borowsky LH, et al. A new risk scheme to predict ischemic stroke and other thromboembolism in atrial fibrillation: the ATRIA study stroke risk score. J Am Heart Assoc 2013; 2: e000250.

29. Piccini JP, Stevens SR, Chang Y, et al. Renal dysfunction as a predictor of stroke and systemic embolism in patients with nonvalvular atrial fibrillation: validation of the R(2)CHADS(2) index in the ROCKET AF (Rivaroxaban Once-daily, oral, direct factor Xa inhibition Compared with vitamin $\mathrm{K}$ antagonism for prevention of stroke and Embolism Trial in Atrial Fibrillation) and ATRIA (An Ticoagulation and Risk factors In Atrial fibrillation) study cohorts. Circulation 2013; 127 : 224-32.

30. Wolf PA, Abbott RD, Kannel WB. Atrial fibrillation as an independent risk factor for stroke: the Framingham Study. Stroke 1991; 22: 983-8.

31. Pugh D, Pugh J, Mead GE. Attitudes of physicians regarding anticoagulation for atrial fibrillation: a systematic review. Age Ageing 2011; 40: 675-83. 
M. Gawałko, M. Budnik, B. Uziębło-Życzkowska, I. Gorczyca, P. Krzesiński, P. Scisło, J. Kochanowski, A. Michalska, O. Jelonek, K. Starzyk, A. Jurek, M. Kiliszek, B. Wożakowska-Kapłon, G. Gielerak, K.J. Filipiak, G. Opolski, A. Kapłon-Cieślicka

32. Ogilvie IM, Welner SA, Cowell W, Lip GY. Ischaemic stroke and bleeding rates in 'real-world' atrial fibrillation patients. Thromb Haemost 2011; 106: 34-44.

33. Rewiuk K, Bednarz S, Faryan P, Grodzicki T. Knowledge of antithrombotic prophylaxis among patients with atrial fibrillation. Cardiol J 2007; 14: 44-9.

34. Kirchhof P, Ammentorp B, Darius H, et al. Management of atrial fibrillation in seven European countries after the publication of the 2010 ESC guidelines on atrial fibrillation: primary results of the PREvention of thromboemolic events - European Registry in Atrial Fibrillation (PREFER in AF). Europace 2014; 16: 6-14.

35. Apenteng PN, Gao H, Hobbs FR, Fitzmaurice DA, Investigators UG-A, Committee G-AS. Temporal trends in an tithrombotic treatment of real-world UK patients with newly diagnosed atrial fibrillation: findings from the GARFIELD-AF registry. BMJ Open 2018; 8: e018905.

36. Connolly SJ, Ezekowitz MD, Yusuf S, et al. Dabigatran versus warfarin in patients with atrial fibrillation. $N$ Engl J Med 2009; 361: 1139-51.

37. Eikelboom JW, Wallentin L, Connolly SJ, et al. Risk of bleeding with 2 doses of dabigatran compared with warfarin in older and younger patients with atrial fibrillation: an analysis of the randomized evaluation of long-term anticoagulant therapy (RE-LY) trial. Circulation 2011; 123: 2363-72.

38. Almutairi AR, Zhou L, Gellad WF, et al. Effectiveness and safety of non-vitamin $\mathrm{K}$ antagonist oral anticoagulants for atrial fibrillation and venous thromboembolism: a systematic review and meta-analyses. Clin Ther 2017; 39: 1456-78 e36.

39. Wilson D, Seiffge DJ, Traenka C, et al. Outcome of intracerebral hemorrhage associated with different oral anticoagulants. Neurology 2017; 88: 1693-700.

40. Granger CB, Alexander JH, McMurray JJ, et al. Apixaban versus warfarin in patients with atrial fibrillation. $N$ Engl J Med 2011; 365: 981-92.

41. Cardoso R, Knijnik L, Bhonsale A, et al. An updated meta-analysis of novel oral anticoagulants versus vitamin $\mathrm{K}$ antagonists for uninterrupted anticoagulation in atrial fibrillation catheter ablation. Heart Rhythm 2018; 15: 107-15.

42. Coleman Cl, Briere JB, Fauchier L, et al. Meta-analysis of real-world evidence comparing non-vitamin $\mathrm{K}$ antagonist oral anticoagulants with vitamin $\mathrm{K}$ antagonists for the treatment of patients with non-valvular atrial fibrillation. J Mark Access Health Policy 2019; 7: 1574541.

43. Patti G, Pecen L, Lucerna M, et al. Net clinical benefit of non-vitamin $\mathrm{K}$ antagonist vs. vitamin $\mathrm{K}$ antagonist anticoagulants in elderly patients with atrial fibrillation. Am J Med 2019; 132: 749-57 e5.

44. Caldeira D, Nunes-Ferreira A, Rodrigues R, Vicente E, Pinto FJ, Ferreira JJ. Non-vitamin K antagonist oral anticoagulants in elderly patients with atrial fibrillation: a systematic review with meta-analysis and trial sequential analysis. Arch Gerontol Geriatr 2019; 81: 209-14.

45. Mitchell A, Watson MC, Welsh T, McGrogan A. Effectiveness and safety of direct oral anticoagulants versus vitamin $\mathrm{K}$ antagonists for people aged 75 years and over with atrial fibrillation: a systematic review and meta-analyses of observational studies. J Clin Med 2019, 8: 554 